\title{
Origins of subcalcic garnets and their relation to diamond forming fluids - Case studies from Ekati (NWT-Canada) and Murowa (Zimbabwe).
}

\author{
D. Graham Pearson and Ofra Klein-BenDavid \\ Department of Earth Sciences, Durham University, Durham, UK
}

\section{Introduction}

G10 garnets are unusual mantle derived Cr-rich, subcalcic garnets. They are found as inclusions within P-type diamonds and also as rare garnet grains within dunitic and harzburgitic xenoliths, making them an important tool in the investigation of diamond genesis and in prospecting. G10 garnets display some of the most extreme $\mathrm{Sr}$ and $\mathrm{Nd}$ isotopic variations so far recorded in mantle materials. $\varepsilon_{\mathrm{Nd}}$ values of subcalcic garnets span a range of over 60 epsilon units and the $\mathrm{Sr}$ isotopic composition of subcalcic garnets can be extremely radiogenic, ranging up to ${ }^{87} \mathrm{Sr} /{ }^{86} \mathrm{Sr}=0.75510$ (Pearson et al., 2003 and references there in). These ratios are unsupported by the low $\mathrm{Rb} / \mathrm{Sr}$ ratios of the garnets indicating crystallization from an enriched precursor and/or metasomatism by fractionated radiogenic fluids.

G10 garnets commonly have a sinusoidal CI normalized REE pattern which peaks at Nd-Sm. This differs from the "normal" lherzolitic garnet pattern which displays a positive slope from $\mathrm{LREE}_{\mathrm{N}}$ to $\mathrm{MREE}_{\mathrm{N}}$ and fairly flat MREE $\mathrm{N}_{\mathrm{N}}-\mathrm{HREE}_{\mathrm{N}}$. Stachel et al. (2004) suggested that the transition from a "normal” to a sinusoidal REE pattern reflects a transition from melt metasomatism to metasomatism by LREE rich C-H-O fluids. The variable REE patterns have also been related to garnet fractionation from metasomatic melts that have gone through percolative fractional crystallization (Burgess and Harte, 1999). Alternatively, a disequilibrium origin has been suggested as the source for the sinusoidal patterns
(Shimizu and Richardson, 1987) implying that the xenolitic garnets crystallized shortly before sampling by the kimberlite.

This work attempts to determine the metasomatic history reflected by G10 garnets from Ekati and Murowa, and examines the potential relationship between the garnet metasomatic agent and diamond forming fluids sampled within fibrous diamonds.

\section{Results}

Major element composition: Eight Ekati garnets were analyzed for major elements (WDS-EPMA). They are extremely depleted in $\mathrm{CaO}$ and high in $\mathrm{Cr}_{2} \mathrm{O}_{3}$ with good correlations between $\mathrm{Cr}_{2} \mathrm{O}_{3}, \mathrm{Al}_{2} \mathrm{O}_{3}$ and $\mathrm{CaO}$. The positive correlation between $\mathrm{CaO}$ and $\mathrm{Cr}_{2} \mathrm{O}_{3}$ (Fig 1) indicates derivation from a constant depth. Applying the $\mathrm{CaO}-\mathrm{Cr}_{2} \mathrm{O}_{3}$ barometer of (Grutter et al., 2006; 38 $\mathrm{mW} / \mathrm{m}^{2}$ ) yields an average $4.9 \pm 0.09 \mathrm{GPa}$ equilibration pressure, which lies well within the diamond stability field of typical cratonic geotherms. The "Ca intercept" values (Grütter et al., 2004) of the Ekati garnets vary between 0.9 and $1.7 \mathrm{wt} \%$ and indicate a dunitic paragenesis. These futures are in accordance with garnet derivation from a depleted section of the Lac de Gras lithosphere (Griffin et al., 1999).

Trace element compositions of the garnets were analyzed using an Element II ICP-MS.

REE patterns: CI normalized REE patterns of Ekati and Murowa garnets are sinusoidal with a maxima shifting between $\mathrm{Pr}$ and Sm-Eu. The $(\mathrm{La} / \mathrm{Nd})_{\mathrm{CI}}$ ratio ranges between 0.01 and 0.6 .

Multi element patterns: Most of the garnets are 
Figure 1:

$\mathrm{Cr}_{2} \mathrm{O}_{3}$ versus $\mathrm{CaO}$ in the Ekati garnets

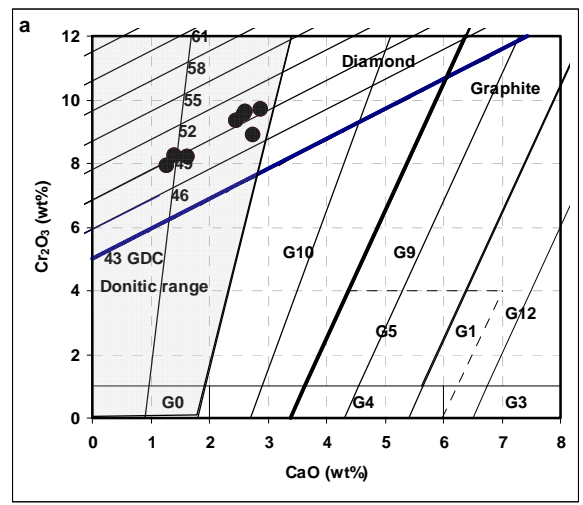

depleted in $\mathrm{Ti}$ and $\mathrm{Sr}$ and enriched in $\mathrm{U}$ relative to primitive mantle. The Ti concentration in the Ekati garnets increases from highly depleted values to slightly enriched values (80 to $312 \mathrm{ppm}$ ) and is attributed to increasing degrees of metasomatism.

Sr, Nd and $\mathrm{Hf}$ isotopic compositions: The $\mathrm{Sr}$ isotopic compositions of the garnets (Triton-TIMS) vary between ${ }^{87} \mathrm{Sr} /{ }^{86} \mathrm{Sr}=0.70326 \pm 6$ and $0.731191 \pm 8$. These radiogenic $\mathrm{Sr}$ isotopic ratios are unsupported by their low ${ }^{87} \mathrm{Rb} /{ }^{86} \mathrm{Sr}$ ratios. Nd isotopic compositions (Neptune ICP-MS-MC) were measured for 8 samples. Age corrected $\varepsilon_{\mathrm{Nd}}$ values in 4 Ekati samples and 3 of the Murowa samples fall in the range of $\varepsilon_{\mathrm{Nd}}=-8.1$ to 27.1. One Murowa sample has a radiogenic $\varepsilon_{\mathrm{Nd538}}$ value of +2.5 .

Only one sample from Ekati contained sufficient Hf to allow measurement of its Hf isotopic composition (Neptune ICP-MS-MC). $\varepsilon_{\mathrm{Hf}}$ for this sample is -61.6 and the CHUR model age calculated for this value is 3521 Ma. This $\varepsilon_{\mathrm{Hf}}$ value is the least radiogenic value so far recorded for a mantle derived sample.

\section{Discussion}

The timing of formation and metasomatism of the Ekati garnets: The very low $\varepsilon_{\mathrm{Nd}}$ and $\varepsilon_{\mathrm{Hf}}$ values of the G10 garnets together with their radiogenic $\mathrm{Sr}$ isotopic compositions indicate an early enrichment in LILE and LREE in the lithospheric mantle. The enrichment event may have occurred during a major subduction event or as a result of asthenospheric alkali melt enrichment events in the Archean. Subduction events have sub-accreted Cr-rich oceanic lithospheric mantle to the cratonic roots as a protolith for the formation of G10 garnets.
At least three scenarios can be envisioned for the crystallization and metasomatism of the G10 garnets:

1. G10 garnets inherit their radiogenic Sr isotopic composition from an enriched precursor:

Early lithospheric enrichment event and early garnet formation: Garnet forms from an enriched protolith soon after subduction. Because garnet is low in $\mathrm{Rb}$, the protolith must have possessed highly elevated $\mathrm{Rb} / \mathrm{Sr}$ ratios prior to garnet formation, in order to evolve very radiogenic $\mathrm{Sr}$ in a relatively short time. Such high $\mathrm{Rb} / \mathrm{Sr}$ ratios will be hard to achieve even via the subduction of continental material.

Early lithospheric enrichment event and late garnet formation: In this model the lithospheric enrichment event took place in ancient times, but garnet formation from the enriched protolith was much more recent. This requires only moderate $\mathrm{Rb} / \mathrm{Sr}$ ratios in the metasomatic agent source that could be derived from percolating alkali melts of asthenospheric origin or subducted material.

\section{G10 garnets over printed by LREE rich,} radiogenic metasomatic agent: in this scenario G10 garnets have crystallized from subducted lithospheric Cr-rich material. The garnets were subsequently overprinted by a metasomatic, LILE-LREE rich agent that had matured in the lithosphere to yield the highly radiogenic $\mathrm{Sr}$ and non-radiogenic $\mathrm{Nd}$ isotopic compositions observed in the garnets.

\section{G10 garnets progressively enriched in ${ }^{87} \mathrm{Sr} /{ }^{86} \mathrm{Sr}$ by} several metasomatic events: In this model garnet are periodically metasomatized by different radiogenic agents. However, the good correlation between the trace element composition of the garnets and their $\mathrm{Sr}$ isotopic composition in the Ekati garnets would have been altered and erased upon continued multiple metasomatic events, thus, at least in the case on the Ekati G10 garnets such model is less likely

Over the years several authors have suggested that sinusoidal REE patterns in G10 garnets represent disequilibrium partitioning. In the current study an indication of trace element (Ce) variation was observed in triplicate analysis of one Ekati garnet. The models 
evoking late garnet formation or a late metasomatic event are consistent with the disequilibrium assumption.

Burgess and Harte (1999) have proposed garnet precipitation from melts that have gone through percolative fractional crystallization (PFC). The Ekati G10 garnets appear to have been derived from a similar depth and probably represent a narrow temperature range. According to the PFC model, they should have similar REE patterns and $\mathrm{Sr}$ isotopic composition. Yet they show probably the largest range in REE contents of all garnets and display huge isotopic diversity. The trace element and isotope signatures suggest that the processes involved in their formation are multi-stage and cannot be fitted with the evolution of a single melt.

The origin of the metasomatic agent and the link between G10-garnets and diamond forming fluids

The strongest argument for the genetic relation between G10 garnets and diamond forming fluids, other than their occurrence as inclusions in diamonds, comes from their isotopic compositions. G10 garnets are characterised by extremely low $\varepsilon_{\mathrm{Nd}}$ and have among the most radiogenic ${ }^{87} \mathrm{Sr} /{ }^{86} \mathrm{Sr}$ values retrieved from mantle samples. New ${ }^{87} \mathrm{Sr} /{ }^{86} \mathrm{Sr}$ and $\varepsilon_{\mathrm{Nd}}$ measurements of fibrous diamond forming fluids from various locations (Klein-BenDavid at al., this volume) have yielded ${ }^{87} \mathrm{Sr} /{ }^{86} \mathrm{Sr}$ values between MORB values and up to ${ }^{87} \mathrm{Sr} /{ }^{86} \mathrm{Sr}=072325 \pm 3$. The $\varepsilon_{\mathrm{Nd}}$ values of the fluids are extremely un-radiogenic and yield CHUR model ages of $\sim 2$ Ga. Few other mantle lithologies match this isotopic diversity.

Glimmerites are mica-rich bodies that display low $\varepsilon_{\mathrm{Nd}}$ values and have radiogenic ${ }^{87} \mathrm{Sr} /{ }^{86} \mathrm{Sr}$ values. They are enriched in LILE that show strongly fractionated REE patterns. Selective melting or dehydration of glimmerite rich zones in the mantle can yield fluids with extreme isotopic compositions and trace element contents. Glimmerites can contain phlogopite, apatite and graphite, and are ultrapotassic. Enrichment in $\mathrm{K}$ and $\mathrm{P}$, carbon and water are among

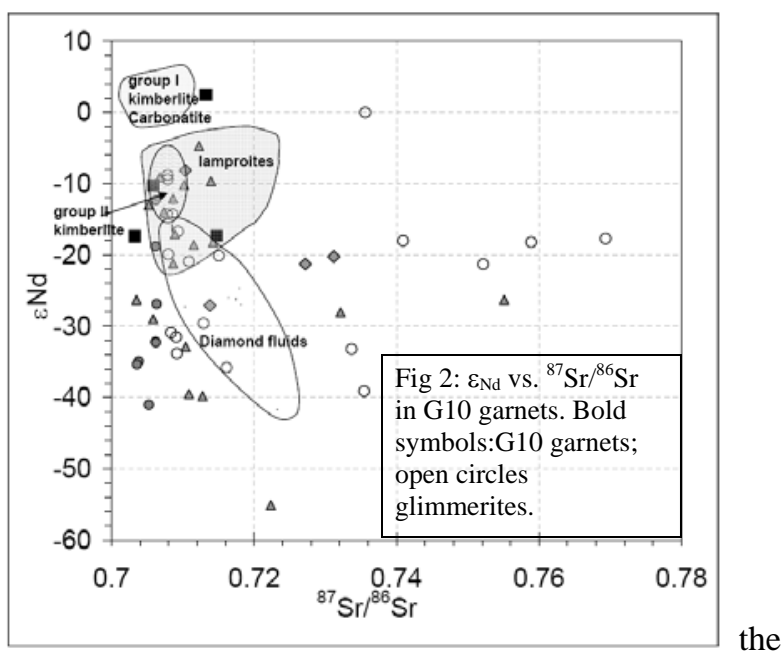

characteristic features of diamond-forming fluids. Moreover, the fact that carbonate-rich veins were observed within glimmerites further strengthens the connection to diamond forming fluids, as the latter are highly enriched in carbonate. Thus, diamond forming fluids can be derived from glimmerites and can be also be considered as a major metasomatic fluid capable of producing the isotopic signatures seen in G10 garnets. Such fluids may also be major metasomatic components responsible for altering much of the lithospheric mantle.

\section{References}

Burgess S. R. and Harte B. 1999. Tracing lithosphere evolution through the analysis of heterogeneous G9/G10 garnet in peridotite xenoliths, I: Major element chemistry. Proceedings of the 7th Kimberlite Conference (Dawson volume), 66-80.

Griffin W. L., Doyle B. J., Ryan C. G., Pearson N. J., O'Reilly S. Y., Davies R., Kivi K., Van Achterbergh E., and Natapov L. M. 1999. Layered mantle lithosphere in the Lac de Gras area, Slave Craton: Composition, structure and origin. Journal of Petrology 40(5), 705-727.

Grutter H., Latti D., and Menzies A. 2006. Cr-saturation arrays in concentrate garnet compositions from kimberlite and their use in mantle barometry. Journal of Petrology 47(4), 801-820.

Grutter H. S., Gurney J. J., Menzies A. H., and Winter F. 2004. An updated classification scheme for mantle-derived garnet, for use by diamond explorers. Lithos 77(1-4), 841-857.

Pearson D. G., Canil D. C., and Shirey S. B. 2003. Mantle samples included in volcanic rocks: xenoliths and diamonds. In Treatise on Geochemistry, Vol. 2, pp. 171-275. Elsevier.

Shimizu N. and Richardson S. H. 1987. Trace-element abundance patterns of garnet inclusions in peridotite-suite diamonds. Geochimica et Cosmochimica Acta 51(3), 755-758.

Stachel T., Aulbach S., Brey G. P., Harris J. W., Leost I., Tappert R., and Viljoen K. S. 2004. The trace element composition of silicate inclusions in diamonds: a review. Lithos 77(1-4), 1-19. 